Brit. J. industr. Med., 1959, 16, 297.

\title{
AN ANALYSIS OF SOME OBSERVATIONS OF THERMAL COMFORT IN AN EQUATORIAL CLIMATE
}

\author{
BY \\ C. G. WEBB \\ From the Building Research Station, Garston, Watford, Herts.
}

(RECEIVED FOR PUBLICATION SEPTEMBER 26, 1958)

The analysis is introduced by a brief account of the development of work on thermal comfort. The observations, which are fully described in relation to the interior climates which were experienced, were made in Singapore in 1949-50. The climate of Singapore is typical of the equator, being warm, damp and windless; and the annual variation is almost negligible. Buildings are unheated, of an open type, and shaded from the sun and sky.

A multiple regression equation has been derived, giving the thermal effect on a number of subjects of variations in the air temperature, the water vapour pressure, and the air velocity within the ranges experienced. The implications of the equation are discussed, and a climatic index is derived from it which is similar in definition to the widely used "effective temperature " scale, but shows a better correlation with thermal sensation. The new index is named the Singapore index.

At a further stage the thermal sensation scale is simplified for the purpose of probit analysis. The probit regressions of discomfort due to warmth and cold are separately given in relation to the new index, and are combined to yield a thermal comfort graph from which the optimum is obtained and explored. A comfort chart for the rapid assessment of these humid climates is supplied, and an alternative form of the index equation is given which is more suitable for rapid calculation.

It appears desirable in an equatorial climate to attempt to minimize discomfort by allowing to some extent for individual thermal requirements, and the benefits of a suitable climatic spread within a room are described.

The principal factors governing thermal comfort and discomfort were familiar to the ancients, and Hippocrates (400 B.C.) has left a description of physiological climate in terms of temperature, humidity, wind, and radiation which is still qualitatively valid. However, there remained the triple problem: that of measuring the physical variables with appropriate accuracy, of combining them in a single, manageable, climatic index, and of determining the optimum value of the index for human beings living under specified conditions.

Measurements of the general type required for the solution of this problem began to be made in the seventeenth and eighteenth centuries, but indoor climates, almost as much as opinions about them, were found to be elusive. Under natural conditions climates are not uniform but are variable, and their variability affects comfort. Instruments which are reliable under laboratory conditions are found under natural conditions to be affected by several of the physical variables simultaneously. Human beings are indispensable as subjects, but show marked idiosyncrasy, are semi-permanently affected by the climates to which they are subjected, and themselves often appreciably alter the climate in a room. From the first measurements of the temperature of the ambient air made in Florence and Pekin in the midseventeenth century, to the delineation of a suitable set of apparatus for the measurement of an indoor climate by Bedford in the 1930s was a period commensurate with the large amount of development that was needed.

The familiarity of the problem of warming a room, and the immediate availability of a rough and ready solution to it, concealed the scientific difficulties. The room itself contains the four three-dimensional fields, of which two, temperature and humidity, are scalar, but the others, air movement and radiation, are partly vector; none of them is constant or uniform, as a rule, and much of the variation is local, 
transient, complex, and interrelated. The climatic measurements, which must often be made under difficult conditions without the refinements of the laboratory, need to represent the changing climatic situation with sufficient, but without excessive or irrelevant detail and with a directness and simplicity that will permit the simultaneous use of human beings as subjects. The presence or absence of thermal discomfort, on the other hand, is a matter of opinion which has not so far been related with certainty to any physiological measurement which can be made on the human subject. The opinions of a number of subjects must therefore be elicited, with care to avoid prejudice, and subsequently submitted to statistical treatment.

In such a situation, it is not surprising that several attempts have been made to find a short cut, either by inventing a single instrument which would measure physiological climate directly, or by devising a universal climatic index which would combine the relevant physical factors. An early comfort meter was the Heberden heated thermometer of 1826; others have been the kata thermometer (Hill, 1914), later used as an anemometer; the globe thermometer (Vernon, 1930), and the eupatheoscope (Dufton, 1932). Climatic indices have included effective temperature (Houghten and Yagloglou, 1923), equivalent warmth (Bedford, 1936), and resultant temperature (Missenard, 1944). Indices of physiological stress have also been devised for use under conditions of extreme discomfort, a matter which is not, however, at present under discussion.

Bedford, in 1936, subjected the available instruments and indices to a crucial test, that of estimating the correlation between their respective indications and the comfort votes of British factory workers, according to a scale he had devised, the votes being carefully elicited in a well-designed interview. The test showed that the available indices for interior climate were no improvement on the plain' measurement of the air temperature but the popularity of the established indices seems to have been unaffected. Bedford also obtained a multiple regression equation relating his comfort votes to the physical variables.

The internal climate in a room may be measured adequately and conveniently by means of the simple, self-contained set of apparatus described by Bedford (1946), which consisted of a dry- and a wet-bulb thermometer mounted in a whirling psychrometer, a kata thermometer, and a globe thermometer. The first named thermometers are ventilated by whirling and their readings give the air temperature unaffected by radiation, and the depression of the wet bulb, from which the humidity may be calculated using psychrometric tables and Regnault's equation. The kata thermometer is a thermometer with a very large bulb which is gently warmed, and from an observation of the time it takes to cool over a specified temperature interval, in air at a known temperature, the rate of air movement can be deduced. The globe thermometer is an ordinary thermometer with its bulb enclosed in a large blackened copper ball. The elevation or depression of the reading of this thermometer relative to that of the ordinary dry-bulb thermometer in air moving at a known rate gives a measure of the flux of radiant heat.

The populations of the tropics are peculiarly subject to thermal discomfort, due basically to the warmth of the climates in which they live but often consisting, for secondary reasons connected with the lightness of their clothing and the meagreness of their diet, of a sensation of cold. This fact, coupled with the prevalence of overcrowding in tropical cities, has long been recognized as constituting, in relation to human happiness and even to health, a problem of some magnitude, one which by 1940 was ripe for solution. It was possible at that time to do no more than discuss it, but it was discussed, in particular by the writer and Dr. N. Canton, Health Officer of Singapore. The discussion begun in 1940, was resumed in 1946-7, and as a result a project, planned while on leave in England in 1948, was put into operation in Singapore in 1949-50. The resulting observations, a part only of the original, uncompleted project, have since 1957 been completely analysed and the result is here presented.

The observations are relatively few in number in comparison with those obtained in similar projects in cooler climates, but it appears that with lightlyclothed subjects very large numbers of observations may be less necessary, though they are still, of course, desirable. The results which have been obtained are of adequate precision for a first estimate to be made of the requirements of the population of a lowlatitude country. It is hoped that the procedure described may be followed by similar projects, leading to the gradual building up of a realistic climatic index covering other warm climates, and of a body of information regarding the thermal requirements of peoples of tropical nations living under varied conditions.

\section{The Observations}

The project from which these data were derived was designed to investigate the indoor climate of Singapore, and the response of the acclimatized population to it under the normal, undisturbed conditions of ordinary daily life. About 20 persons who had long been resident 
in Malaya*, all healthy adult males of middle-class status, with an English education, were trained in the use of simple instruments for the measurement of the temperature, humidity, and velocity of the ambient air, viz., the whirling psychrometer and the kata thermometer, and were shown how to keep a laboratory record. They were supplied (Bedford, 1946), with a Casella whirling psychrometer and a small bottle of distilled water; a $100-95^{\circ} \mathrm{F}$. plain glass Hicks kata thermometer (also in some cases with a $130-125^{\circ} \mathrm{F}$. silvered Hicks kata thermometer) and a stopwatch, a thermos flask, and a small retort stand; a 6-inch diameter globe thermometer and a typed card bearing the thermal sensation scale shown in Table 1.

TABLE 1

SCALE OF THERMAL SENSATION

\begin{tabular}{l|c}
\hline \multicolumn{1}{c|}{ Overall Thermal Sensation } & Code Number \\
\hline Excessively cold & 0 \\
Cold & 1 \\
Cool & 2 \\
Comfortably cool & 3 \\
Comfortable and neither cool nor warm & 4 \\
Comfortably warm & 5 \\
Warm & 6 \\
Hot & 7 \\
Excessively hot & 8 \\
\hline
\end{tabular}

The observers were asked to record their assessments of their own overall thermal sensation according to the scale, and the subsequent readings of the thermometers and the kata cooling time, at intervals of half an hour for roughly six-hour periods, in their own homes and offices, with as little disturbance as possible to the ordinary daily routine. It was the intention to concentrate on the daily extremes of climate in the early morning and afternoon, and on the known periods of climatic difficulty at the equinoxes.

Readings continued as opportunity offered from May, 1949, to April, 1950, the set of apparatus being passed from one subject-observer to another. The distribution of the observations in time is depicted in Figs. $1 \mathrm{a}$ and $1 \mathrm{~b}$.

The observers were asked to record any events that might have a thermal significance, such as changes in

*The subjects chosen as being fully acclimatized were 14 members of the staff of the Singapore Municipal Health Department and six of the Physics Department of the University of Malaya. There were seven Chinese, seven Eurasians of one quarter, or less, of recent European blood, four Europeans, one Indian, and one Malay. The data analysed are from 14 subjects, of whom five were Chinese, seven Eurasian, one Indian, and one European. Two of the Chinese returned only half the average quantity of data and one Eurasian returned three times that quantity. The proportion of Chinese in the city was about twice that in the sample. Subsequent attempts to detect in these data any connexion between race and discomfort were unsuccessful.

The country of origin of nine of the 14 subjects was Singapore or Malaya, of two China, and of two others India and Europe respectively, that of the remaining subject being unrecorded. In seven of the first-named nine cases, both parents were born in Malaya or a neighbouring country and in one case all the grandparents were also.

All but one of the subjects, the European, had been continuously in Malaya for at least 10 years before making the observations, and several had spent their whole lives there. The European had had six months' climatic leave ending two years before the observations began. Before that he had been in Singapore continuously for seven years and altogether for 20 .
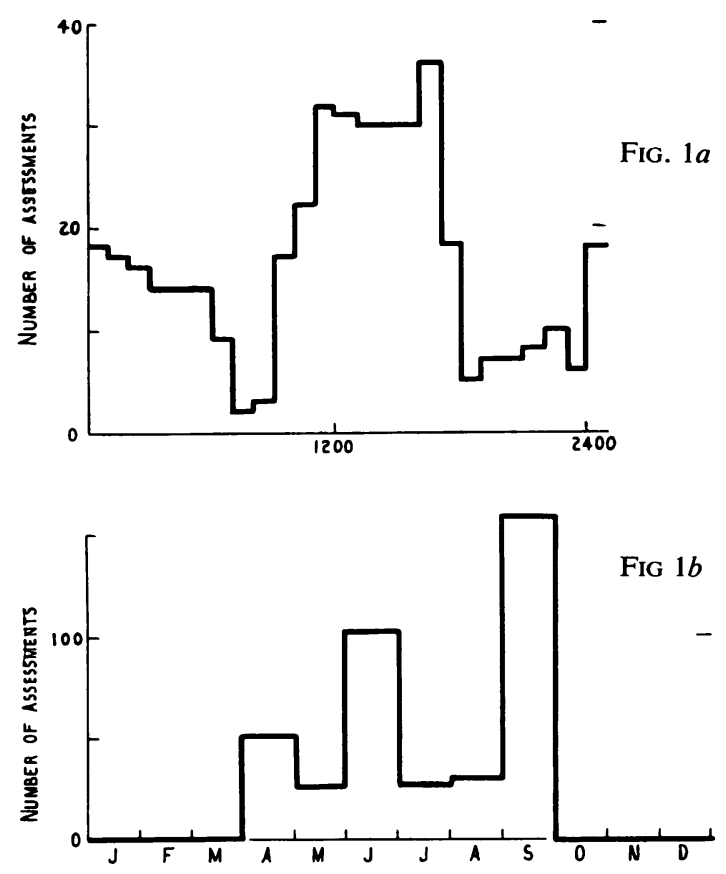

Fig. 1.-The distribution of assessments relative $(a)$ to time of day (b) to the months of the year.

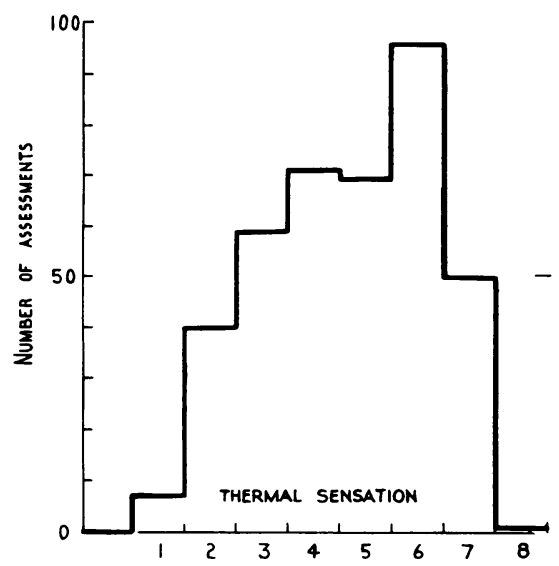

Fig. 2.-The frequency distribution of assessments relative to the thermal sensation scale.

clothing, in the weather, the opening or closing of doors, the use of fans, sensible perspiration, etc. Dimensioned drawings of the location of the instruments and a description of the premises were added to the record. Simultaneous meteorological observations from Kallang Airport were supplied by the Malayan Meteorological Service.

Activity was light, the observers being occupied mainly in taking the observations. They wore the ordinary informal cotton clothing of warm climates, 
consisting of a short-sleeved shirt, underpants, trousers, and shoes, with or without socks and necktie, by day: and pyjama trousers, with or without the jacket, by night.

The total number of complete sets of observations, each consisting of a thermal assessment, a wet- and a dry-bulb temperature, a globe temperature, and a kata cooling time, plus other information, was 463. As a preliminary move these were reduced to measurements of the air temperature, the water vapour pressure, and the air velocity by the use of nomograms. The globe temperature was found to agree closely (s.d. $\pm \frac{1}{2}{ }^{\circ} \mathrm{F}$.) with the air temperature and was subsequently ignored. At a later date, 65 sets of observations having been excluded for incompleteness and five for obvious error, the reduction was repeated on 393 sets from 14 observers, using Regnault's formula for the water vapour pressure (assuming a corrected barometric height of $758 \mathrm{~mm}$. of mercury), Bedford's equations (Bedford, 1948) for the 329 observations made on the $100-95^{\circ} \mathrm{F}$. kata thermometer, and Koch and Kaplan's equations (Koch and Kaplan, 1958) for the remainder made on the $130-125^{\circ} \mathrm{F}$. instrument.

The frequency distribution of assessments relative to the thermal sensation scale is shown in Fig. 2. The bias towards a feeling of warmth will be noticed and the relative absence of extremes, to the extent that, apart from a single vote of eight, only seven of the nine pos- sible assessments were utilized. These features are believed to be due to the slight preponderance of daytime readings and the gap in the observations from September, 1949, to April, 1950, on the one hand, and to the fact that the indoor climate was to some extent under the control of the subject on the other.

The main features of the basic data may be seen by inspecting the correlation tables of the thermal assessment with the air temperature (Table 2 ), with the water vapour pressure (Table 3 ), with the air velocity (normalized by extracting the square root) (Table 4) and the correlation table of the air temperature with the square root of the air velocity (Table 5). Owing to a serious post-war shortage of electric fans the indoor air velocities were unusually low, fans being absent from all the premises used, with one exception.

\section{Analysis I}

The data were fitted to an equation of the form $\mathrm{C}=\mathrm{at}+\mathrm{bp}+\mathrm{cv}^{\frac{1}{2}}+\mathrm{d}$, where $\mathrm{C}$ is the thermal assessment on the scale of Table $1 ; \mathrm{a}, \mathrm{b}, \mathrm{c}$, and $\mathrm{d}$ are numerical coefficients to be determined; while $t$ is the Fahrenheit air temperature, $p$ the water vapour pressure in $\mathrm{mm}$. of mercury, and $v$ the air velocity in feet per minute. The method employed was as follows: In order to eliminate as far as possible the effects of personal idiosyncrasies the

TABLE 2

CORRELATION TABLE FOR THERMAL ASSESSMENT AND AIR TEMPERATURE

\begin{tabular}{|c|c|c|c|c|c|c|c|c|c|c|c|}
\hline \multirow{2}{*}{$\begin{array}{l}\text { Air Temperature } \\
\text { to nearest }{ }^{\circ} \mathrm{F} \text {. }\end{array}$} & & \multicolumn{9}{|c|}{ Thermal Assessment } & \multirow{2}{*}{ Totals } \\
\hline & & 0 & 1 & 2 & 3 & 4 & 5 & 6 & 7 & 8 & \\
\hline $\begin{array}{l}92 \\
91 \\
90 \\
89 \\
88 \\
87 \\
86 \\
85 \\
84 \\
83 \\
82 \\
81 \\
80 \\
79 \\
78\end{array}$ & & & $\begin{array}{l}2 \\
3 \\
2\end{array}$ & $\begin{array}{r}1 \\
\\
6 \\
4 \\
2 \\
1 \\
9 \\
10 \\
7\end{array}$ & $\begin{array}{r}1 \\
\\
3 \\
1 \\
4 \\
6 \\
17 \\
1 \\
5 \\
2 \\
9 \\
8 \\
2\end{array}$ & $\begin{array}{r}1 \\
4 \\
4 \\
1 \\
10 \\
6 \\
11 \\
11 \\
12 \\
1 \\
9 \\
1\end{array}$ & $\begin{array}{r}2 \\
2 \\
10 \\
11 \\
14 \\
11 \\
10 \\
3 \\
6\end{array}$ & $\begin{array}{r}2 \\
\\
2 \\
18 \\
10 \\
16 \\
20 \\
9 \\
7 \\
4 \\
8\end{array}$ & $\begin{array}{r}2 \\
1 \\
3 \\
5 \\
4 \\
16 \\
12 \\
4 \\
3\end{array}$ & 1 & $\begin{array}{r}4 \\
2 \\
4 \\
11 \\
13 \\
39 \\
47 \\
43 \\
71 \\
36 \\
36 \\
11 \\
43 \\
22 \\
11\end{array}$ \\
\hline Totals & $\ldots$ & $\mathbf{0}$ & 7 & 40 & 59 & 71 & 69 & 96 & 50 & 1 & 393 \\
\hline
\end{tabular}

TABLE 3

CORRELATION TABLE FOR THERMAL ASSESSMENT AND WATER VAPOUR PRESSURE

\begin{tabular}{|c|c|c|c|c|c|c|c|c|c|c|c|}
\hline \multirow{2}{*}{$\begin{array}{l}\text { Water } \\
\text { Vapour Pressure } \\
\text { to nearest mm. }\end{array}$} & & \multicolumn{9}{|c|}{ Thermal Assessment } & \multirow{2}{*}{ Totals } \\
\hline & & 0 & 1 & 2 & 3 & 4. & 5 & 6 & 7 & 8 & \\
\hline $\begin{array}{l}30 \\
29 \\
28 \\
27 \\
26 \\
25 \\
24 \\
23 \\
22\end{array}$ & & & $\begin{array}{l}2 \\
5\end{array}$ & $\begin{array}{r}12 \\
10 \\
12 \\
6\end{array}$ & $\begin{array}{r}1 \\
5 \\
13 \\
22 \\
13 \\
5\end{array}$ & $\begin{array}{r}1 \\
7 \\
19 \\
21 \\
18 \\
5\end{array}$ & $\begin{array}{r}8 \\
21 \\
29 \\
9 \\
2\end{array}$ & $\begin{array}{r}1 \\
4 \\
3 \\
14 \\
33 \\
29 \\
12\end{array}$ & $\begin{array}{r}4 \\
9 \\
11 \\
5 \\
9 \\
5 \\
4 \\
3\end{array}$ & 1 & $\begin{array}{r}4 \\
10 \\
16 \\
9 \\
43 \\
104 \\
115 \\
69 \\
23\end{array}$ \\
\hline Totals & $\cdots$ & 0 & 7 & 40 & 59 & 71 & 69 & 96 & 50 & 1 & 393 \\
\hline
\end{tabular}


TABLE 4

CORRELATION TABLE FOR THERMAL ASSESSMENT AND SQUARE ROOT OF AIR VELOCITY

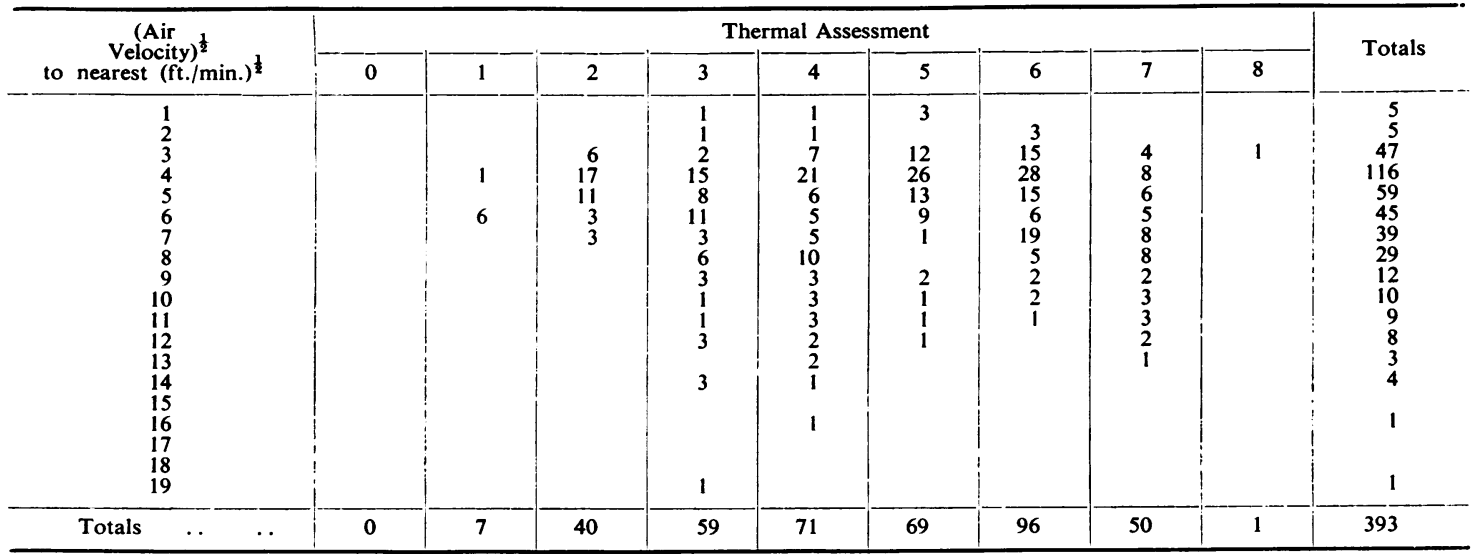

TABLE 5

CORRELATION TABLE BETWEEN AIR TEMPERATURE AND SQUARE ROOT OF AIR VELOCITY

\begin{tabular}{|c|c|c|c|c|c|c|c|c|c|c|c|c|c|c|c|c|}
\hline \multirow{2}{*}{$\begin{array}{c}\text { (Air } \\
\text { Velocity) } \\
\text { to nearest (ft. } / \mathrm{min} .)^{\frac{1}{2}}\end{array}$} & \multicolumn{15}{|c|}{ Air Temperature to Nearest ${ }^{\circ} \mathrm{F}$. } & \multirow{2}{*}{ Totals } \\
\hline & 78 & 79 & 80 & 81 & 82 & 83 & 84 & 85 & 86 & 87 & 88 & 89 & 90 & 91 & 92 & \\
\hline $\begin{array}{r}1 \\
2 \\
3 \\
4 \\
5 \\
6 \\
7 \\
8 \\
9 \\
10 \\
11 \\
12 \\
13 \\
14 \\
15 \\
16 \\
17 \\
18 \\
19\end{array}$ & $\begin{array}{l}1 \\
3 \\
2 \\
5\end{array}$ & $\begin{array}{l}1 \\
4 \\
2 \\
6 \\
7\end{array}$ & $\begin{array}{r}1 \\
10 \\
19 \\
6 \\
4 \\
1 \\
1 \\
1\end{array}$ & $\begin{array}{l}1 \\
3 \\
4 \\
2 \\
1\end{array}$ & $\begin{array}{r}1 \\
4 \\
14 \\
5 \\
6 \\
2 \\
1 \\
1\end{array}$ & $\begin{array}{r}3 \\
4 \\
12 \\
7 \\
2 \\
2 \\
6\end{array}$ & $\begin{array}{r}1 \\
10 \\
25 \\
11 \\
2 \\
7 \\
6 \\
4 \\
3\end{array}$ & $\begin{array}{r}2 \\
3 \\
13 \\
7 \\
9 \\
2 \\
2 \\
2 \\
2 \\
1\end{array}$ & $\begin{array}{r}9 \\
18 \\
5 \\
3 \\
4 \\
3 \\
2 \\
1 \\
2\end{array}$ & $\begin{array}{r}2 \\
7 \\
4 \\
5 \\
12 \\
5 \\
1 \\
2 \\
1\end{array}$ & $\begin{array}{l}5 \\
5 \\
1 \\
1 \\
1\end{array}$ & $\begin{array}{l}2 \\
1 \\
2 \\
3 \\
2 \\
1\end{array}$ & $\begin{array}{l}1 \\
1 \\
1\end{array}$ & $\begin{array}{l}1 \\
1\end{array}$ & $\begin{array}{l}1 \\
1\end{array}$ & $\begin{array}{r}5 \\
5 \\
47 \\
116 \\
59 \\
45 \\
39 \\
29 \\
12 \\
10 \\
9 \\
8 \\
3 \\
4 \\
1 \\
\end{array}$ \\
\hline Totals .. & 11 & 22 & 43 & 11 & 36 & 36 & 71 & 43 & 47 & 39 & 13 & 11 & 4 & 2 & 4 & 393 \\
\hline
\end{tabular}

thermal assessment was considered to be of the form $\mathrm{C}=\overline{\mathrm{C}}+(\mathrm{C}-\overline{\mathrm{C}})$ where $\overline{\mathrm{C}}$ was the average thermal assessment obtained by a single observer in a particular batch of observations. It was found that $(C-\bar{C})$ was distributed approximately normally with respect to the sensation scale, whereas the distribution of $\overline{\mathrm{C}}$ had no recognizable form (Figs. $3 a$ and $3 b)$. The variation of $(C-\bar{C})$ is to a marked extent related to the variations in temperature, water vapour pressure, and air velocity, but not, of course, to the observer or the place of observation. It measures in fact the average reaction of the observers to changes in the physical climate.

The correlations of $(C-\bar{C})$ with $(t-\bar{t}),(p-\bar{p})$, and $\left(v^{\frac{1}{2}}-\overline{\left.v^{\frac{1}{2}}\right)}\right.$, where $\bar{t}, \bar{p}$, and $\overline{v^{\frac{1}{2}}}$ are the average values of $t, p$, and $v^{\frac{1}{2}}$ for the separate batches of observations, were then examined. The coefficients 


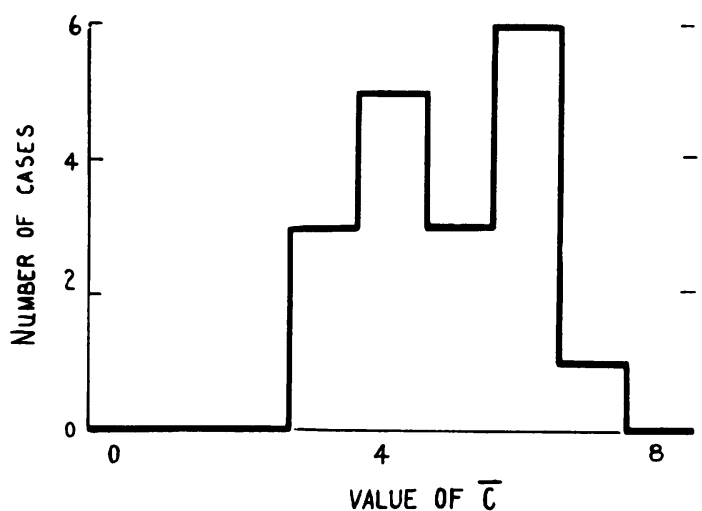

FIG. 3a.-Distribution of 18 values of $\overline{\mathbf{C}}$.

shown in the third column of Table 6 and indicate very highly significant correlation in all three cases unaffected by the correlation between temperature and air velocity which is noticeable, for instance, in Table 5.

The regression coefficients were next estimated within the batches of observations using an analysis of covariance, i.e., in effect analysing the variation of $(C-\bar{C})$ on $(t-\bar{t}),(p-\bar{p})$ and $\left(v^{\frac{1}{2}}-\overline{v^{\frac{1}{2}}}\right)$. The estimates which were obtained are given in Table 7 .

TABLE 7

REGRESSION COEFFICIENTS OF THERMAL ASSESSMENT ON PHYSICAL VARIABLES

\begin{tabular}{l|c|c|c}
\hline \multicolumn{1}{c|}{ Variable } & $\begin{array}{c}\text { Regression Coefficient } \\
\text { of Thermal Assessment } \\
\text { on the Variable }\end{array}$ & $\begin{array}{c}\text { Standard } \\
\text { Error }\end{array}$ & $t$-value \\
\hline $\begin{array}{l}\text { Temperature } \\
\text { Vapour pressure } \\
\text { (Air velocity) }\end{array}$ & +0.256 & 0.020 & 12.56 \\
\hline
\end{tabular}

The values of $\bar{t}, \bar{p}$, and $\bar{v} \frac{1}{2}$ affect that of the blank term in the regression equation, which ranged from -22.74 to -19.40 with an unweighted average of $-21 \cdot 19$.

An additional term in $v^{\frac{1}{2}} \cdot t$ was considered for inclusion in the regression equation, but the correlation of this product with the thermal assessment was found to be due to the correlation with $v^{\frac{1}{2}}$ and $t$ separately, and a comparison of mean squares showed that such a term could safely be ignored.

The regression equation is therefore

$$
\begin{aligned}
C & =0.256 \mathrm{t}+0.218 \mathrm{p}-0.103 \mathrm{v} \frac{1}{2}-21 \cdot 19 \\
& =\quad \mathrm{a} \cdot \mathrm{t}+\quad \mathrm{b} \cdot \mathrm{p}+\mathrm{c} \cdot \mathrm{v}^{\frac{1}{2}}+\mathrm{d}
\end{aligned}
$$

Now an equation of this type is rather informative. It gives the equivalence (Houghten and Yagloglou, 1923) between water vapour pressure and temperature in their effects on thermal sensation, viz., an increase of $1 \mathrm{~mm}$. of mercury in the water vapour pressure is equivalent to an increase of temperature

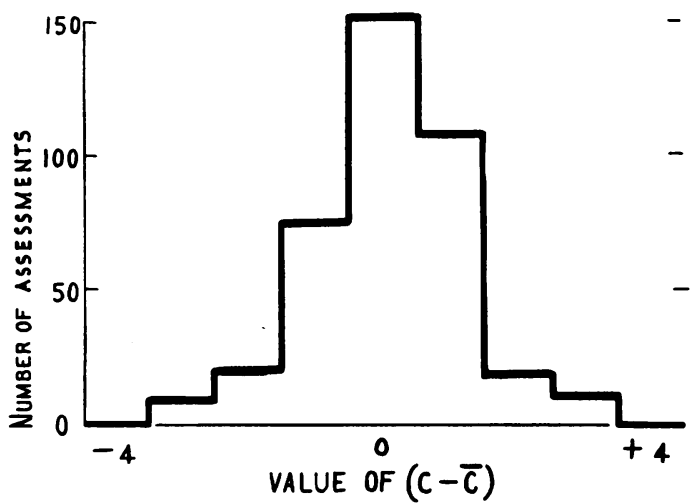

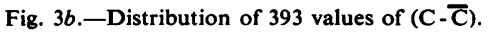

of $b / a=0.85^{\circ} \mathrm{F}$. Similarly an increase of 1 (foot per minute) $)^{\frac{1}{2}}$ in the square root of the air velocity is equivalent to a decrease in the air temperature of $-\mathrm{c} / \mathrm{a}=0.40^{\circ} \mathrm{F}$.

Consequently the equation implies, and would enable one to construct, a climatic scale combining the three physical variables in proportion to their effects on thermal sensation. The scale might take any convenient form and, for instance, it might be defined somewhat on the lines of "effective temperature" (Yaglou, 1949), as the temperature of still, saturated air which produces the same overall thermal sensation. If we accept this definition, and suppose that over a sufficient range for the present purpose the saturated water vapour pressure may be represented by the expression

$$
\text { we may write } \begin{aligned}
\mathrm{p}_{\text {sat }} & =e+f \cdot t \\
\mathrm{C} & =a \cdot \theta+b(e+f \cdot \theta)+d \\
& =(a+b f) \theta+(b e+d)
\end{aligned}
$$

where $\theta$ is the value of the climatic index, and the conditions $v=0$ and $p=p_{\text {sat }}$ have been inserted. Solving for $\theta$ we have

$$
\theta=\frac{C-(b e+d)}{(a+b f)}
$$

We may eliminate $C$ between equations (i) and (iv), obtaining

$$
\begin{aligned}
\theta & =\frac{a}{a+b f} \cdot t+\frac{b}{a+b f} \cdot p+\frac{c}{a+b f} \cdot v \frac{1}{2}-\frac{b e}{a+b f} \\
& =0.574 t+0.488 p-0.231 v^{\frac{1}{2}}+21.23
\end{aligned}
$$

in the present case, where $\mathrm{p}_{\mathrm{sat}}=-43.46+0.873 \mathrm{t}$.

The index $\theta$, as defined by equation (v), might be expected to be especially suitable as a measure of climate under the experimental conditions which have been described, and in particular to be superior to the air temperature in this respect. This expectation is confirmed by an examination of the analyses of $C$, which is a linear function of $\theta$ so that the significance tests give the same results for the two 
TABLE 8

ANALYSIS OF VARIANCE

\begin{tabular}{c|c|c|c}
\hline Source of Variation & Sums of Squares & D.F. & $\begin{array}{c}\text { Mean } \\
\text { Squares }\end{array}$ \\
\hline $\begin{array}{c}\text { Residual variability of C when } \\
\text { temperature alone is considered }\end{array}$ & 321.8 & 374 & - \\
$\begin{array}{c}\text { Residual variability of C when } \\
\text { vapour pressure and air velocity }\end{array}$ & 276.7 & 372 & 0.74 \\
$\begin{array}{c}\text { are also considered } \\
\text { Improvement in second analysis }\end{array}$ & $45 \cdot 1$ & 2 & 22.54 \\
\hline
\end{tabular}

variables. The residual variance of $C$ is noticeably reduced if, after the effect of temperature has been removed, the effects of vapour pressure and air velocity are subsequently allowed for (Table 8 ). Fisher's $\mathrm{z}$ test (Fisher, 1954) shows the improvement to be highly significant.

The reduced residual variability presumably contains contributions from variations in clothing and in thermal idiosyncrasy, and also from errors in measurement and it is not to be expected that any consideration of climatic factors will suffice to reduce it to a very low value.

The improvement which has been achieved is not only statistically significant, it is a very useful one in comparison with the improvements previously obtained. For instance, the widely used effective temperature scale failed to give any improvement on temperature when tested by Bedford (1936), by means of the correlation coefficient. The coefficient between the sensation of coolness and the dry-bulb air temperature was $-0.48 \pm 0.010$ and that between coolness and the effective temperature was precisely the same. Ho (1952) found, with Singapore data, that the correlation coefficient between the sensation of warmth and the dry-bulb air temperature was +0.52 and that between warmth and the effective temperature was +0.55 ; while the writer found closely similar values to those of $\mathrm{Ho}$, the standard errors of \pm 0.035 and \pm 0.033 , and the result of the Fisher $\mathrm{z}$ test, showing the improvement to be insignificant.

In view of this satisfactory property it is proposed to make use of $\theta$ as defined in equation ( $v$ ) as a new climatic index, and to name it the Singapore index. The correlation table between the thermal assessment and the value of the Singapore index calculated from the observed values of the physical variables $t, p$, and $v^{\frac{1}{2}}$ follows (Table 9). The coefficient of correlation is $+0.65 \pm 0.027$, and the improvement on Table 2 is self evident.

The multiple regression equation gives further information which in effect enables one to locate thermal sensation levels on the new climatic scale. The regression of $\mathrm{C}$ on $\theta$, for instance, is represented by the equation $\mathrm{C}=(\mathrm{a}+\mathrm{bf}) \boldsymbol{\theta}+(\mathrm{be}+\mathrm{d})=$ $0.447 \theta-30.68$, which indicates that the average thermal assessment will be neutral, i.e., $C=4$, at $\theta=77 \cdot 6^{\circ} \mathrm{F}$. However, a more profitable alternative is available.

\section{Analysis II}

Following Chrenko (1953a, 1953b, 1955) and Bedford (1954), it is clear that a thermal sensation scale may, with convenience and some logical advantage, be treated not as a numerical scale but as one involving degrees of approach to a quantal response of thermal discomfort. In this sense votes on the scale in Table 1 would be considered to lie in one of two categories. The first category would indicate the absence of discomfort due to warmth, and would include votes 0 (excessively cold) to 5 (comfortably warm); while the second category would indicate the presence of warmth discomfort and include votes 6 (warm) to 8 (excessively hot). The incidence of the discomfort response would be appropriately analysed by the probit method (Finney, 1947).

The incidence of discomfort due to cold could in

TABLE 9

CORRELATION TABLE OF THERMAL ASSESSMENT WITH SINGAPORE INDEX

\begin{tabular}{|c|c|c|c|c|c|c|c|c|c|c|c|}
\hline \multirow{2}{*}{ 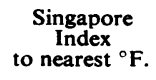 } & & \multicolumn{9}{|c|}{ Thermal Assessment } & \multirow{2}{*}{ Totals } \\
\hline & & 0 & 1 & 2 & 3 & 4 & 5 & 6 & 7 & 8 & \\
\hline $\begin{array}{l}88 \\
87 \\
86 \\
85 \\
84 \\
83 \\
82 \\
81 \\
80 \\
79 \\
78 \\
77 \\
76 \\
75\end{array}$ & & & $\begin{array}{l}2 \\
4 \\
1\end{array}$ & $\begin{array}{r}1 \\
11 \\
2 \\
10 \\
9 \\
5 \\
2\end{array}$ & $\begin{array}{r}1 \\
5 \\
5 \\
11 \\
10 \\
6 \\
9 \\
9 \\
6 \\
2\end{array}$ & $\begin{array}{r}4 \\
22 \\
15 \\
13 \\
7 \\
9 \\
1\end{array}$ & $\begin{array}{r}2 \\
9 \\
18 \\
21 \\
13 \\
5 \\
1\end{array}$ & $\begin{array}{r}1 \\
1 \\
6 \\
21 \\
24 \\
22 \\
14 \\
7\end{array}$ & $\begin{array}{r}2 \\
\\
3 \\
9 \\
14 \\
12 \\
6 \\
3 \\
1\end{array}$ & 1 & $\begin{array}{r}2 \\
1 \\
5 \\
9 \\
22 \\
52 \\
82 \\
82 \\
49 \\
38 \\
30 \\
16 \\
5\end{array}$ \\
\hline Totals & $\ldots$ & 0 & 7 & 40 & 59 & 71 & 69 & 96 & 50 & 1 & 393 \\
\hline
\end{tabular}




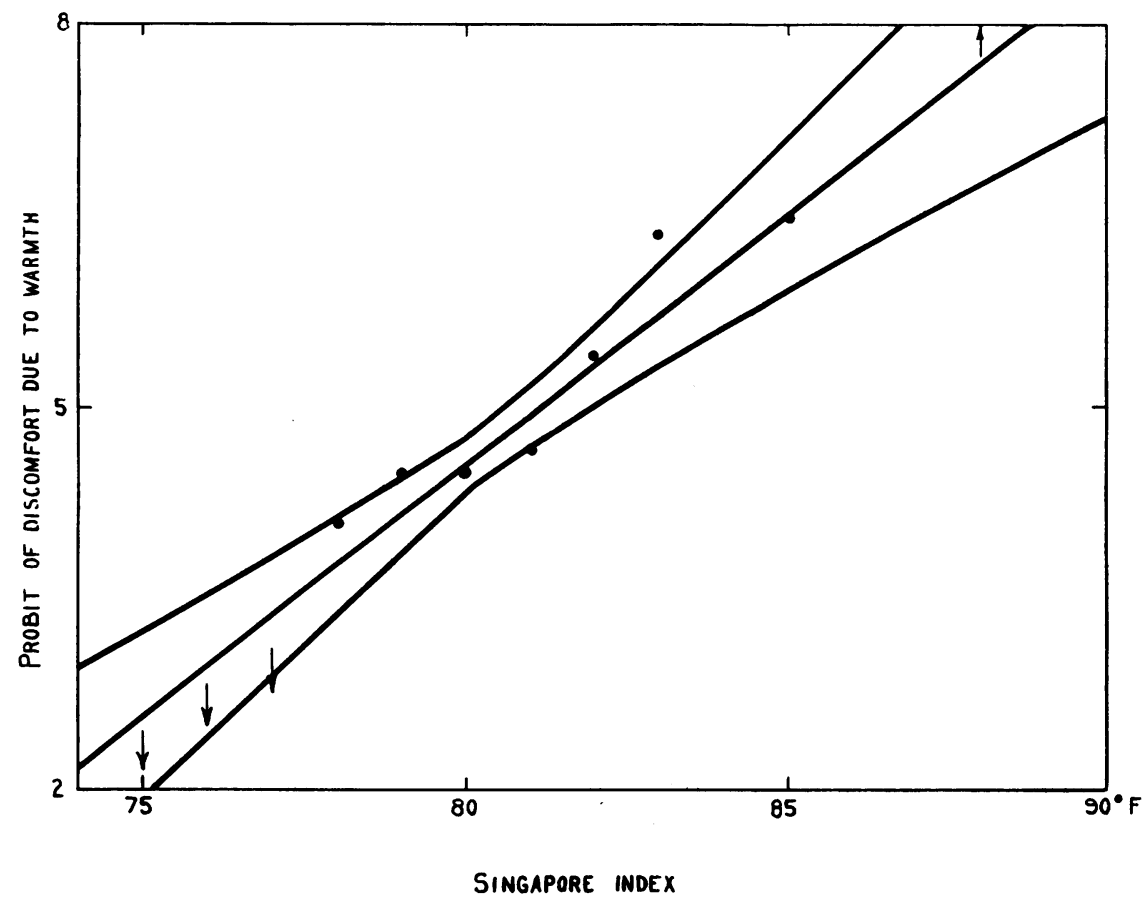

FIG. 4.-Probit regression line, with $95 \%$ fiducial band, for the incidence of discomfort due to warmth relative to the value of the Singapore index.

(1) 


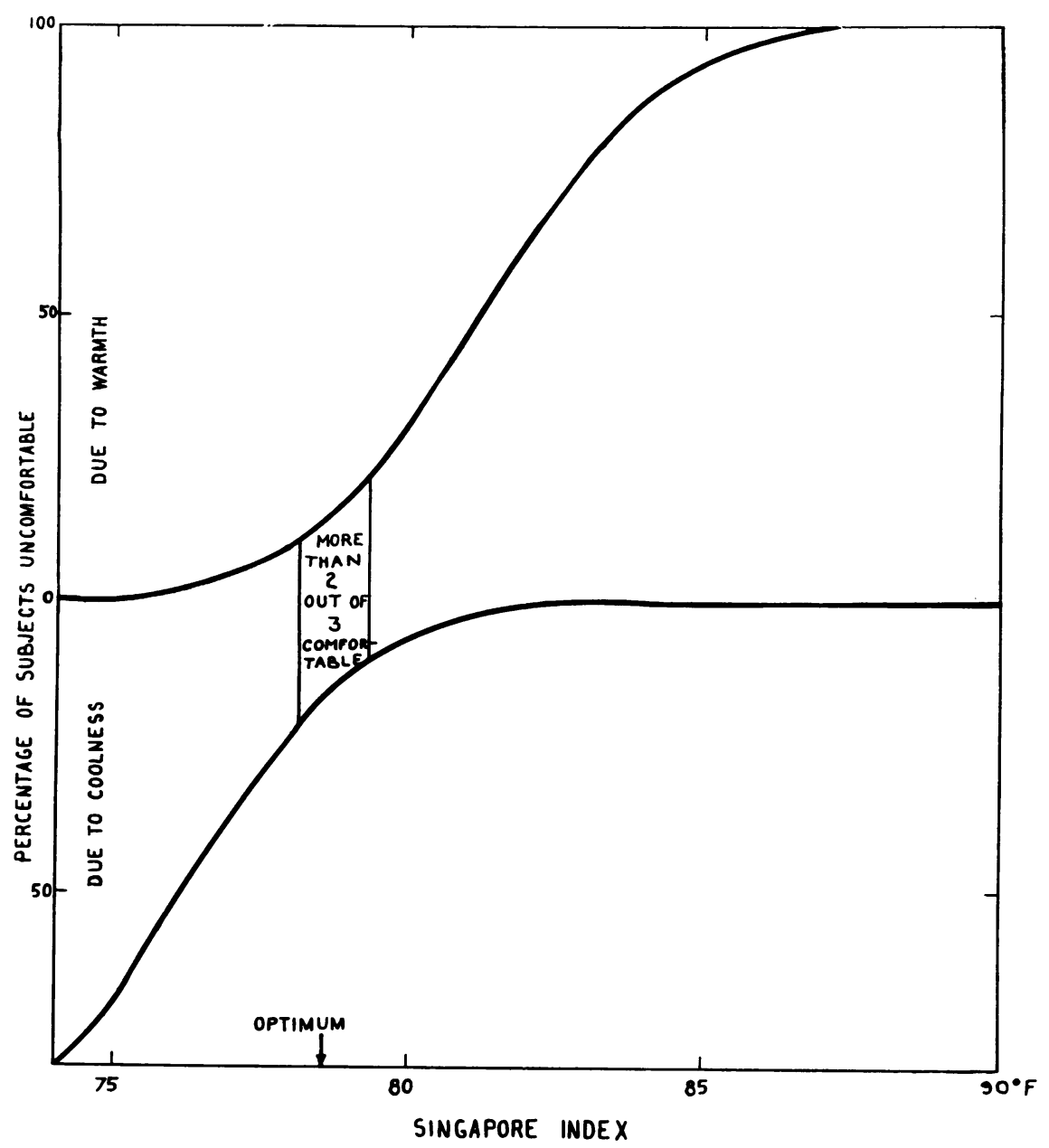

FIG. 6.-The percentage incidence of discomfort due to warmth and cold separately, relative to the Singapore index. The optimum value of the index is marked.

its turn be treated similarly, votes 0 to 2 (cool) being taken to indicate the presence of discomfort due to cold, and votes 3 (comfortably cool) to 8 its absence.

TABLE 10

PROBIT REGRESSION OF WARMTH DISCOMFORT ON SINGAPORE INDEX

\begin{tabular}{l|c}
\hline Slope of the probit regression line & $0.39 \pm 0.05^{\circ} \mathrm{F} .-1$ \\
13.5 & 9 \\
$\begin{array}{l}\chi^{2} \\
\text { Degrees of freedom }\end{array}$ & $81.2 \pm 0.255^{\circ} \mathrm{F}$. \\
\hline
\end{tabular}

TABLE 11

PROBIT REGRESSION OF DISCOMFORT DUE TO COLD ON SINGAPORE INDEX

\begin{tabular}{l|c}
\hline Slope of the probit regression line & $-0.40 \pm 0.06^{\circ} \mathrm{F} .-1$ \\
$x^{2}$ & 8 \\
$\begin{array}{l}\text { Degrees of freedom } \\
\text { Median value of the Singapore index }\end{array}$ & $76.2 \pm 0.5{ }^{\circ} \mathrm{F}$. \\
\hline
\end{tabular}

This procedure has been adopted, and the probit regression lines have been determined for the incidence of discomfort due to warmth and cold separately, relative to the Singapore index. Data for the incidence of discomfort due to warmth are given in Table 10 and the probit regression line and its $95 \%$ fiducial band are illustrated in Fig. 4. Similar data for the response of discomfort due to cold are given in Table 11 and Fig. 5.

Disregarding the sign, the values of the slope are not significantly different. They indicate a similar variability in the population in its response to heat and to cold. The values of $x^{2}$ indicate the presence of a small amount of heterogeneity, which is taken into account in estimating precision.

In order to determine the total incidence of thermal discomfort due to both causes the calculated 


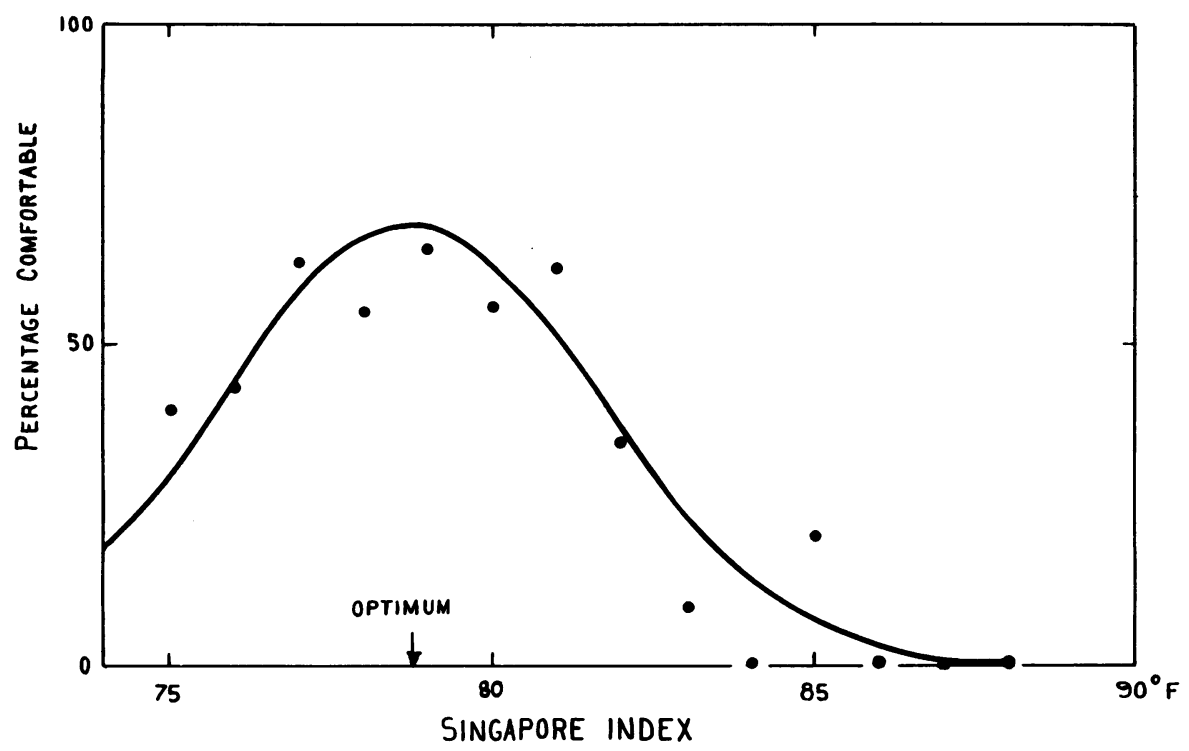

Fig. 7.-The total percentage of subjects feeling no thermal discomfort, relative to the Singapore index. The empirical percentages have been plotted as a check.

probits were converted to percentages (Fig. 6) and added. Subtracting the total from 100 the resulting comfort graph is shown in Fig. 7, where the empirical percentages of subjects casting votes 3 to 5 (indicating the absence of any thermal discomfort) have been plotted for verification.

\section{The Climatic Optimum}

From the graph in Fig. 7 we see that the maximum percentage of subjects who are comfortable at any value of the Singapore index is $68 \%$ at $78 \cdot 7^{\circ} \mathrm{F}$. The precision of the estimate of the optimum climate is indicated by the fiducial limits in Figs. 3 and 4 , giving $95 \%$ limits of about $\pm 1.5 \%$. and $\pm 15 \%$ respectively*. For smallish deviations from the optimum value of $\theta$ the reduction in the percentage of subjects comfortable is $3(\Delta \theta)^{2}$.

As may be seen the comfort graph, not unex-

*In connexion with the estimate of precision it is desirable to consider briefly the way in which the separate batches of data are distributed in Table 9, since there is an assumption implicit in probit analysis that subjects, e.g., insects in a toxicity test, are used only once: or at least that the information from each subject has an equal weight, and has been derived under the same uniformly applied range of test conditions. The latter stipulation especially would be difficult to satisfy under field conditions, and in the present case neither was precisely satisfied. The facts are as follows:

The average number of assessments per observer was $28 \cdot 1$, and $\overline{10}$ out of the 14 observers made between 25 and 31 assessments. Of the remainder, three made 15 or 16 assessments; and one made 55 assessments in one building, and 15 or 16 in each of two others, giving a total of 86 assessments. The last-mentioned observer experienced a full range of climatic variation and appeared to have no marked idiosyncrasy; but the others were subjected to a more restricted range of variation, especially the three who made daytime observations only. pectedly, differs in shape from those obtained in cooler climates. The optimum naturally occurs at a markedly higher temperature, but also the peak is sharper and very much lower. The latter properties could be explained in terms of the lightness of clothing which is appropriate in low latitudes.

For any given value of the Singapore index, including the optimum value, there is a range of interconnected values of the air temperature, the humidity, and the air velocity. From equation (v) we have, for the water vapour pressure at the climatic optimum

$$
\begin{aligned}
\mathrm{p} & =\left[\mathrm{e}+\frac{\theta \text { opt }(\mathrm{a}+\mathrm{bf})}{\mathrm{b}}\right]-\mathrm{at} / \mathrm{b}-\mathrm{cv}^{\frac{1}{2} / \mathrm{b}} \\
& =117.6-1.175 \mathrm{t}+0.47 \mathrm{v} \frac{1}{\mathrm{~s}}
\end{aligned}
$$

The given climate can be defined on the $t, p$ plane by a set of parallel lines representing various constant values of the air velocity, and the optimum

Turning to the probit regression lines, there is good evidence that their slope is correct, since they are members of a family of parallel lines derivable from Table 9. The median value of the Singapore index for the occurrence of discomfort due to warmth is based, in effect, on the observations of seven or eight individuals and so is unlikely to be seriously affected by the idiosyncrasies of any of them The median for discomfort due to cold is, however, less well based, as it comes from only four observers. The value does receive some outside support from symmetry and from the height of the maximum, and is at least uncontradicted by the empirical percentages. In the opinion of the writer it is of value at least temporarily.

The usable information previously quoted, viz., the optimum value of the Singapore index. the maximum percentage of subjects comfortable, and the reduction in the percentage due to a departure from the optimum, are supported by the empirical data and it does not seem probable that the stated precision, contingent on the assumption mentioned, is a serious overestimate. 


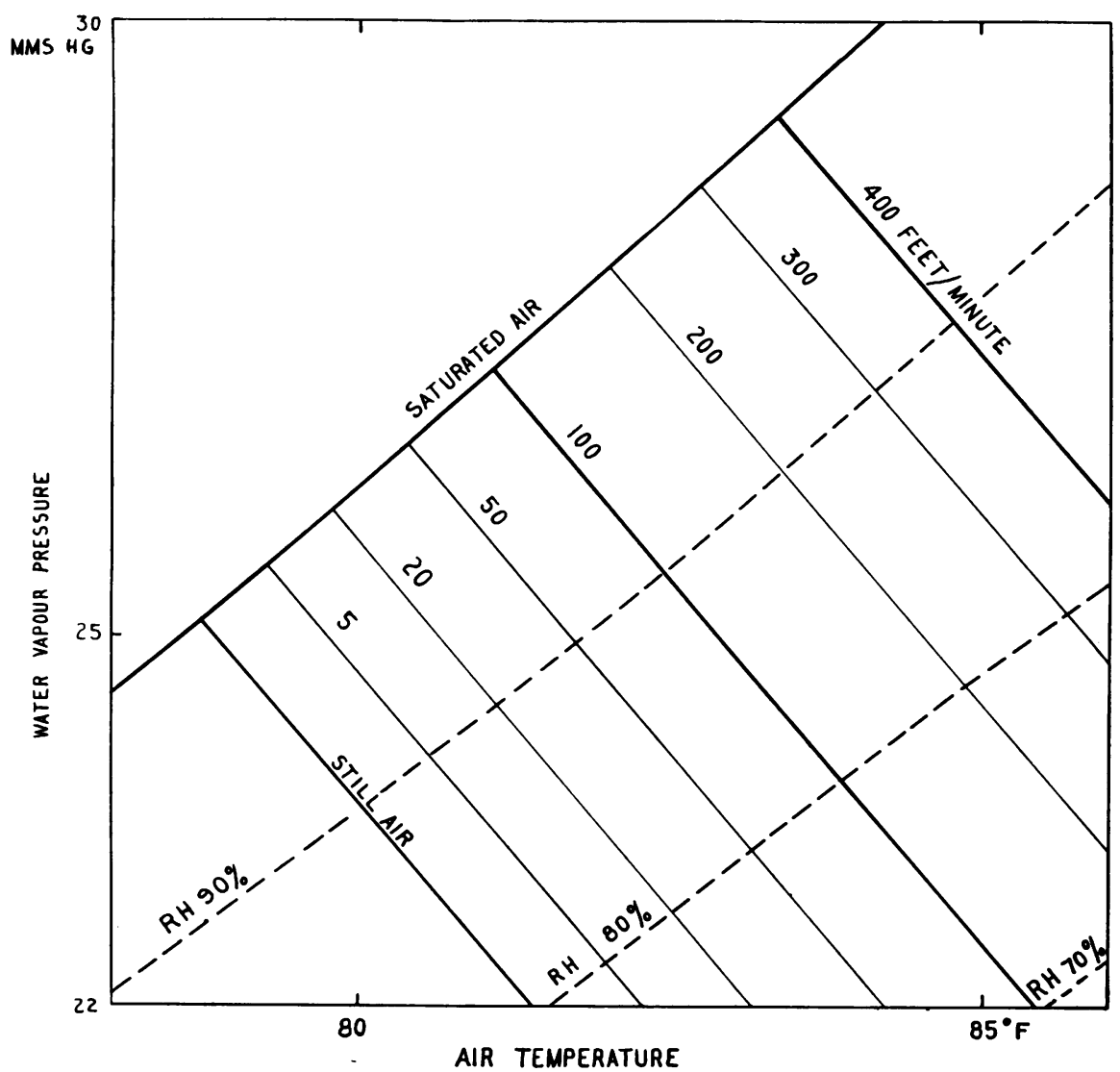

FIG. 8. - The group of climates corresponding to the optimum value of the Singapore index.

climate is depicted in this way in Fig. 7. Within the optimum climate, if it is assumed that the most desirable values of the air velocity and the relative humidity are 40 feet per minute and $70 \%$ respectively, the air temperature most desired by the subjects tested would have been about $84^{\circ} \mathrm{F}$. These ideal conditions were not observed.

\section{Rapid Determination of the Singapore Index}

The Singapore index may, as an alternative to equation (v), be defined in terms of the dry- and wet-bulb temperatures, respectively denoted by $t$ and $t_{w}$, in which case we have

$$
\theta=\frac{(a-b A H) t}{a+b f}+\frac{b(A H+f) t_{w}}{a+b f}-\frac{c v t}{a+b f}
$$

where $\mathrm{H}$ is the height of the mercury barometer and $A$ is the wet-bulb factor, so that when we substitute the previous values for $a, b, c, f$, and $H$ and the value 0.00343 for $A$ we have, in British units,

$$
\theta=0.447 t+0.553 t_{w}-0.231 v \underline{t}
$$

or, with sufficient accuracy for most purposes,

$$
\theta=\frac{1}{2}\left(t+t_{w}\right)-\frac{1}{4} v^{\frac{1}{2}}
$$

These equations, and especially the latter, are obviously more convenient than (v) and should be used whenever possible. The error in equation (viii) is $0.053\left(t-t_{w}\right)-0.019$ vit which is almost always positive, has a value of about $0 \cdot 2^{\circ} \mathrm{F}$. in an ordinary case, and is not more than $0.4^{\circ} \mathrm{F}$. in the most unfavourable case from the present climatic range.

\section{Comfort Chart for Singapore}

The comfort graph in Fig. 7 may be combined with the relevant section of a psychrometric chart to give a convenient means of assessing a warm, humid climate from the point of view of thermal comfort.

For still air we have

$$
\begin{aligned}
p & =-a t / b+(a+b f) \theta / b+e \\
& =-1 \cdot 175 t+2.047 \theta-43.46
\end{aligned}
$$

For successive integral values of $\theta$ we obtain on the $t, p$ chart (Fig. 9) a set of equally spaced parallel 


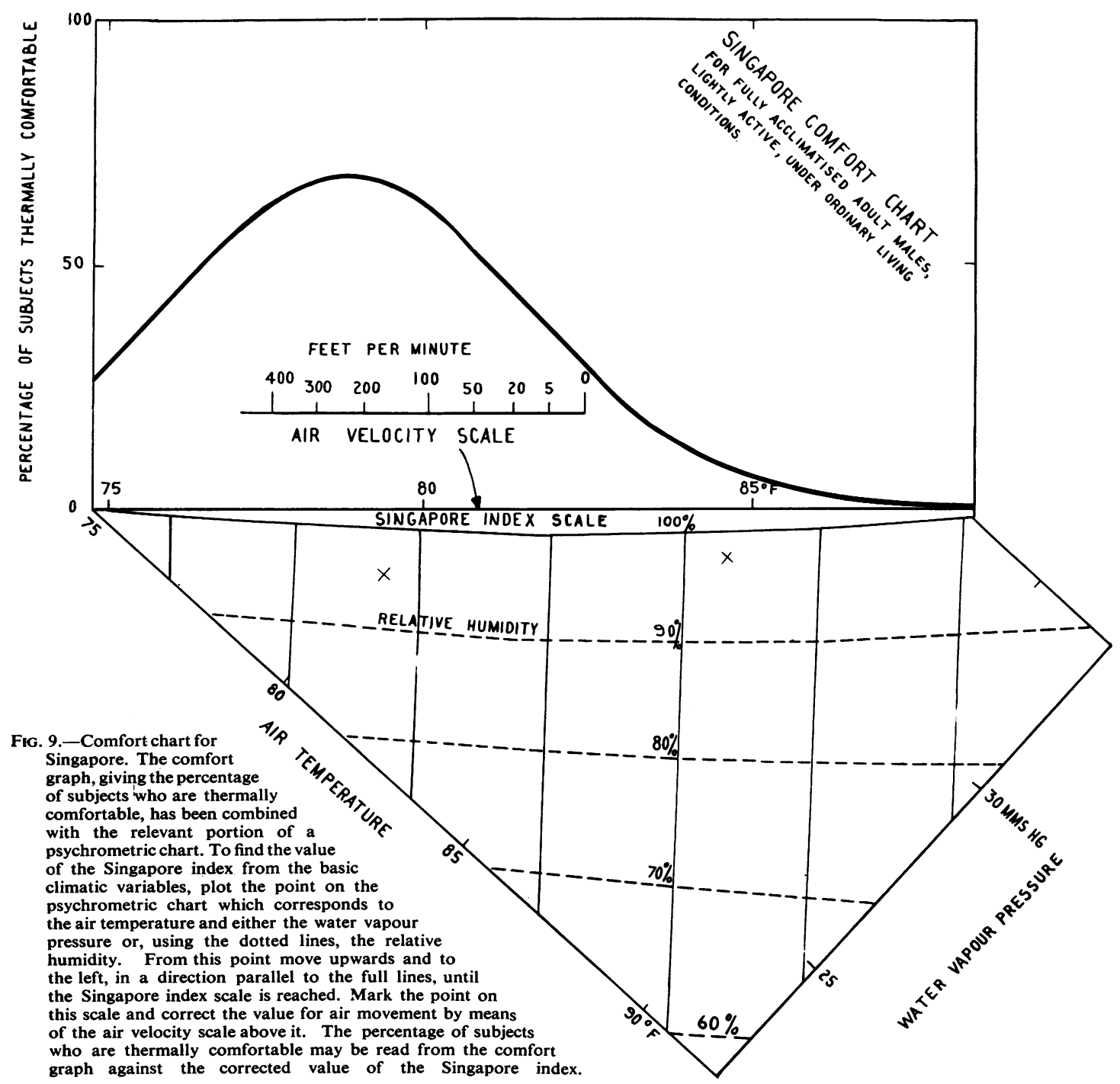

lines of slope $-1.175 \mathrm{~mm}$. $\mathrm{Hg} /{ }^{\circ} \mathrm{F}$. and spacing $1.75^{\circ} \mathrm{F}$. along the $\mathrm{t}$ axis. The intersections with the saturated vapour pressure line occur at the selected values of $\theta$. Lines for even values of $\theta$ from 76 to $88^{\circ} \mathrm{F}$. inclusive are shown in Fig. 9, and a scale of $\theta$ is marked above the saturated vapour line.

The value of $\theta$ now needs to be corrected for the effect of air movement, and this may be done by means of the adjacent scale of air velocity. With the final value of $\theta$ so obtained, the percentage of subjects who are thermally comfortable may be read from the attached comfort graph. The chart may be used (1) to assign a value of the Singapore index to a given climate, and (2) to determine the 


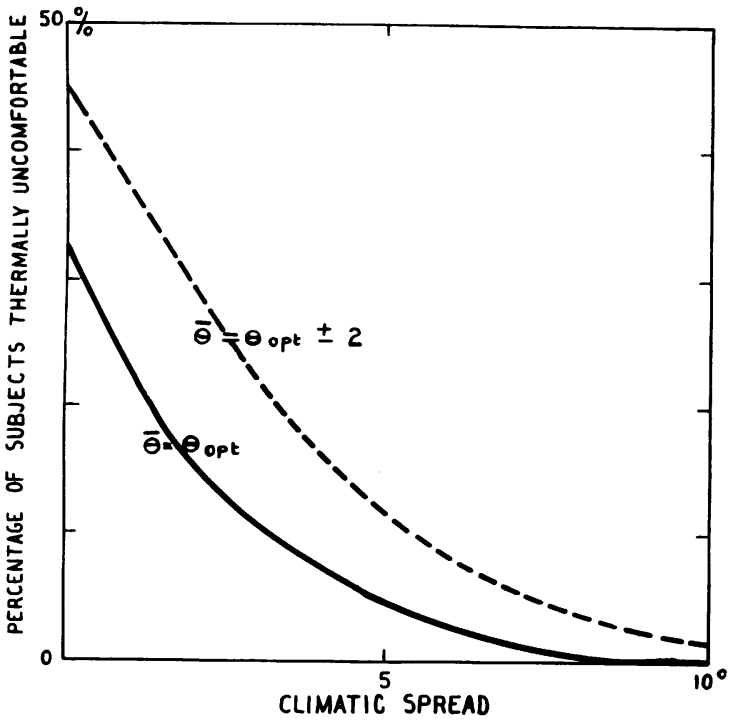

MEASURED ON THE SINGAPORE INDEX

FIG. 10.-The relation between the spread of climate on either side of the optimum, measured on the Singapore index, and the percentage of subjects who are thermally uncomfortable. In the case of the full-line graph the climate is spread equally on each side of the optimum, and in that of the dotted graph it is centred $2{ }^{\circ} \mathrm{F}$., on the Singapore index, away from the optimum.

It is on the other hand undesirable that the spread of climate should be very large in a room that is at all fully occupied, since an excessive spread would clearly either reduce the used area of the room or cause discomfort in a proportion of the occupants. It is therefore advisable to try to estimate the extent of climatic spread that may be expected to be beneficial. This may be done by the use of Fig. 6, as follows: Consider a point on the upper graph at $\theta=\theta_{\mathrm{c}}$. Evidently by reducing the value of $\theta_{\mathrm{c}}$, and so moving the point to the left, it is possible to reduce the percentage of subjects who are warm to a completely negligible figure; at the same time, however, an increasing percentage of subjects, indicated by the lower graph, will feel cool. The latter can become comfortable again if there are available places to which they can move, where $\theta=\theta_{\mathrm{w}}$, a value of the index, to be read from the lower graph, at which the percentage of subjects who feel cool is negligible. The total percentage of subjects who are thermally uncomfortable can obviously be reduced as required by adjusting the limits $\theta_{\mathrm{c}}$ and $\theta_{\mathrm{w}}$. This total will be equal to the sum of the ordinates to the respective graphs at the above-mentioned values of the index.

The relation between the width of the climatic spread, i.e. $\left(\theta_{\mathrm{w}}-\theta_{\mathrm{c}}\right)=\Delta \theta$, and the total percentage of subjects who are uncomfortable, is depicted in Fig. 10. In the case of the full-line graph the spread is centred on the climatic optimum so that $\bar{\theta}=\frac{1}{2}\left(\theta_{\mathrm{w}}+\theta_{\mathrm{c}}\right)=\theta_{\mathrm{opt}}$, and in that of the dotted graph it is centred $2^{\circ} \mathrm{F}$. away, i.e., $\bar{\theta}=\theta_{\mathrm{opt}} \pm 2^{\circ} \mathrm{F}$. From an inspection of the graph it can be seen that a spread of about 4 or $5^{\circ} \mathrm{F}$. in the Singapore index can be highly beneficial, since it may remove thermal discomfort from all but about $5 \%$ of subjects; but on the other hand twice as much spread would be pointless, and might be detrimental. The allocation of floor space to both extremes of climate need not be large, e.g., not more than about $25 \%$ of the total available.

\section{Conclusions}

The warm and humid Singapore indoor climate has been described in relation to the overall thermal sensations of fully acclimatized subjects, and a Singapore index for climate has been defined by the equations

$$
\begin{aligned}
\theta & =0.574 t+0.488 p-0.231 v^{\frac{1}{2}}+21 \cdot 23 \\
& =0.447 t+0.553 t_{w}-0.231 v^{\frac{1}{2}} \\
& \doteqdot \frac{1}{2}\left(t+t_{w}\right)-\frac{1}{4} v^{\frac{1}{2}}
\end{aligned}
$$

where $\theta$ is the value of the index in degrees Fahrenheit, and $t$ and $t_{w}$ are the dry- and wet-bulb temperatures on the same scale, $p$ is the water vapour pressure in millimetres of mercury, and $v$ the air velocity in feet per minute. The index has a coefficient of correlation +0.65 with thermal sensation and is believed to be a significant improvement on any index at present available for climates of this kind.

The incidence of thermal discomfort due to warmth amongst fully acclimatized adult males, lightly active under ordinary living conditions was:

\begin{tabular}{l|c|c|c|c|c|c|c|c}
\hline Singapore index & 74 & 76 & 78 & 80 & 82 & 84 & 86 & $88^{\circ} \mathrm{F}$. \\
\hline $\begin{array}{l}\text { Percentage of subjects } \\
\text { uncomfortable due to } \\
\text { warmth }\end{array}$ & 0 & 2 & 12 & 32 & 63 & 86 & 97 & 100 \\
\hline
\end{tabular}

while the incidence of thermal discomfort due to cold under the same conditions was:

\begin{tabular}{l|c|c|c|c|c|c}
\hline Singapore index & 74 & 76 & 78 & 80 & 82 & $84^{\circ} \mathrm{F}$. \\
\hline $\begin{array}{c}\text { Percentage of subjects uncomfort- } \\
\text { able due to cold }\end{array}$ & 81 & 53 & 23 & 6 & 1 & 0 \\
\hline
\end{tabular}

The optimum value of the Singapore index was $78.7 \pm 3^{\circ} \mathrm{F}$., when $68 \pm 8 \%$ of the subjects were thermally comfortable. For smallish deviations $\Delta \theta$ from the optimum the reduction in the percentage of subjects comfortable was $3(\Delta \theta)^{2}$.

Within the optimum any two of the above- 
mentioned physical variables may vary independently, in accordance with the equation

$$
p=117.6-1 \cdot 175 \mathrm{t}+0.47 \mathrm{v} \text {. }
$$

If it is assumed that the ideal air velocity indoors is 40 feet per minute and the ideal relative humidity $70 \%$, then the air temperature at which discomfort would be a minimum is $84^{\circ} \mathrm{F}$., under the conditions described.

A spread of climate in a single room of about $2^{\circ} \mathrm{F}$. on the Singapore index on each side of the optimum makes it possible to reduce the percentage of subjects who are thermally uncomfortable to 5 .

This note forms part of the programme of the Tropical Building Section of the Building Research Station, and is published by permission of the Director of Building Research. Thanks are due to Miss N. M. Macnaught, B.A., of the Mathematics Division, for carrying out the multiple regression analysis; to Mr. F. S. G. Richards, B.A., of Peterhouse, Cambridge, for checking and finalizing the remaining computations; and to Mr. F. A. Chrenko, of the Environmental Hygiene Research Unit, for valuable criticism and suggestions.

\section{REFERENCES}

Bedford, T. (1936). Rep. industr. Hlth Res. Bd (Lond.), No. 76. H.M.S.O.

(1946). Environmental warmth and its Measurement. M.R.C (War) Memo. No. 17.

(1948). Basic Principles of Ventilation and Heating. H. K. Lewis, London.

- (1954). J. Instn Heat. and Ventil. Engrs, 22, 85.

Chrenko, F. A. (1953a). Ibid., 20, 375.

— (1953b). Brit. J. Psychol. (General Section), 44, 248. (1955). J. Instn Heat. and Ventil. Engrs, 23, 281-295, and Discussion pp. $296-300$

Dufton, A. F. (1932). The Equivalent Temperature of a Room and its Measurement. Bldg. Res. Tech. Paper No. 13

Finney, D. J. (1947). Probit Analysis. University Press, Cambridge.

Fisher, R. A. (1954). Statistical Methods for Research Workers. 12 th ed. Oliver and Boyd, Edinburgh.

Heberden, W. (1826). Phil. Trans. B., 116, Pt. 2, 69.

Hill, L. (1914). Report on Ventilation and the Effect of Open Air and Wind on the Respiratory Metabolism. Rep. Loc. Gov. Bd. Publ. Hith Dept., No. 100.

Hippocrates (400 B.C.). On Waters, Airs and Places.

Ho, P. Y. (1952). J. Instn Heat. and Ventil. Engrs, 20, 196

Houghten, F. C., and Yagloglou, C. P. (1923). Trans. Amer. Soc. Heat. and Ventil. Engrs, 29, 165.

Koch, W., and Kaplan, D. (1958). J. Sci. Instrum., 35, 8.

Missenard, A. (1944). Influence des conditions thermigues ambiantes sur la capacité de travail, la morbidité et la mortalité des ouvriers sur la capacite de travail, la morbidité et la mortalité des ouvriers et la construction des lieux de travail. Com. d'Organisation du

Bâtiment et des Travaux Publics. Circular, series
Vernon, H. M. (1930). J. Physiol. (Lond.), 70, 15P.

Yaglou, C. P. (1949). In Physiology of Heat Regulations and the Science of Clothing, Ch. 9 . pp. 277-287, by L. H. Newburgh.
W. B. Saunders, Philadelphia. 